\title{
Anticoagulation Control with Acenocoumarol or Warfarin in Non-Valvular Atrial Fibrillation in Primary Care (Fantas-TIC Study)
}

\author{
M. Rosa Dalmau Llorca ${ }^{1,2,3,+} \mathbb{C}^{\text {, }}$, Carina Aguilar Martín ${ }^{3,4,5, \dagger}$, Noèlia Carrasco-Querol ${ }^{3,4, * \mathbb{D}}$, \\ Zojaina Hernández Rojas 1,2,3,*, Emma Forcadell Drago ${ }^{1,3}$, Dolores Rodríguez Cumplido ${ }^{3,6}$, \\ Elisabet Castro Blanco ${ }^{2,3}$, Alessandra Queiroga Gonçalves $3,4,7,+(\mathbb{D}$ and José Fernández-Sáez $2,3,4,8,+$ (D)
}

check for

updates

Citation: Dalmau Llorca, M.R.; Aguilar Martín, C.; Carrasco-Querol, N.; Hernández Rojas, Z.; Forcadell Drago, E.; Rodríguez Cumplido, D.; Castro Blanco, E.; Gonçalves, A.Q.; Fernández-Sáez, J. Anticoagulation Control with Acenocoumarol or Warfarin in Non-Valvular Atrial Fibrillation in Primary Care (Fantas-TIC Study). Int. J. Environ. Res. Public Health 2021, 18, 5700 . https://doi.org/10.3390/ijerph 18115700

Academic Editors: Giuseppe Biondi Zoccai and Marco Carmignani

Received: 24 March 2021

Accepted: 18 May 2021

Published: 26 May 2021

Publisher's Note: MDPI stays neutral with regard to jurisdictional claims in published maps and institutional affiliations.

Copyright: (c) 2021 by the authors. Licensee MDPI, Basel, Switzerland. This article is an open access article distributed under the terms and conditions of the Creative Commons Attribution (CC BY) license (https:/ / creativecommons.org/licenses/by/ $4.0 /)$.
1 Equip d'Atenció Primària Terres de l'Ebre, Institut Català de la Salut, 43500 Tortosa, Tarragona, Spain; rdalmau.ebre.ics@gencat.cat (M.R.D.L.); eforcadellg.ebre.ics@gencat.cat (E.F.D.)

2 Campus Terres de l'Ebre, Universitat Rovira i Virgili, 43500 Tortosa, Tarragona, Spain; elicasblan@gmail.com (E.C.B.); jfernandez@idiapjgol.info (J.F.-S.)

3 Primary Care Intervention Evaluation Research Group (GAVINA Research Group), 43500 Tortosa, Tarragona, Spain; caguilar.ebre.ics@gencat.cat (C.A.M.); drficf@gmail.com (D.R.C.); aqueiroga.ebre.ics@gencat.cat (A.Q.G.)

4 Unitat de Suport a la Recerca Terres de l'Ebre, Fundació Institut Universitari per a la Recerca a l'Atenció Primària de Salut Jordi Gol i Gurina (IDIAPJGol), 43500 Tortosa, Tarragona, Spain

5 Unitat d'Avaluació, Direcció d'Atenció Primària Terres de l'Ebre, Institut Català de la Salut, 43500 Tortosa, Tarragona, Spain

6 Hospital Universitari de Bellvitge, Institut Català de la Salut, 08907 Barcelona, Spain

7 Unitat Docent de Medicina de Familia i Comunitària, Tortosa-Terres de l'Ebre, Institut Català de la Salut, 43500 Tortosa, Tarragona, Spain

8 Unitat de Recerca, Gerència Territorial Terres de l’Ebre (Institut Catalá de la Salut), 43500 Tortosa, Tarragona, Spain

* Correspondence: ncarrasco.querol@gmail.com (N.C.-Q.); zhernandezr.ebre.ics@gencat.cat (Z.H.R.); Tel.: +34-977504949 (N.C.-Q.); +34-977504949 (Z.H.R.)

+ Co-senior authors: M.R. Dalmau Llorca, C. Aguilar Martín, A.Q. Gonçalves and J. Fernández-Sáez. M.R. Dalmau Llorca is the Principal Investigator of this study.

Abstract: Introduction: The use of vitamin K antagonists (VKAs) in non-valvular atrial fibrillation (NVAF) is complicated due to the narrow therapeutic margin they present and their unpredictable dose-response relationship. Most studies are based on warfarin, with the results being extrapolated to acenocoumarol. However, studies comparing the two treatments in terms of the degree of anticoagulation control are scarce, justifying the present study. Main factors associated with poor control of time in therapeutic range (TTR) of anticoagulated patients are also studied. Methods: Cross-sectional study, with real-world data from patients treated in primary care (PC). Data were obtained from the System for the Improvement of Research in PC (SIDIAP) database, covering 60,978 NVAFanticoagulated patients from 287 PC centres in 2018. Descriptive statistics were derived, and odds ratios were estimated by multivariate logistic regression. Results: 41,430 patients were considered: $93 \%$ were being treated with acenocoumarol and $7 \%$ with warfarin. There was no difference in poor control of TTR between the two types of VKA treatment, acenocoumarol and warfarin (38.9 vs. 38.4; $p=0.610)$. Poor anticoagulation control was mainly associated with advanced alcoholism $(\mathrm{OR}=1.38)$, liver failure $(\mathrm{OR}=1.37)$ and intracranial haemorrhage $(\mathrm{OR}=1.35)$ as well as female sex, age $<60$ years, cardiovascular history, diabetes mellitus and other variables. Conclusions: There is no association between poor anticoagulation control and the type of VKA treatment administered. Factors associated with poor control of TTR must be considered in clinical practice to improve control and decision-making.

Keywords: atrial fibrillation; vitamin K antagonists; acenocoumarol; warfarin; time in therapeutic range 


\section{Introduction}

Thromboembolic complications of non-valvular atrial fibrillation (NVAF) are prevented by two large groups of oral anticoagulation drugs: vitamin K antagonists (VKAs) and direct-acting oral anticoagulants (DOACs). These treatments play a fundamental role, since they have been associated with a reduction in the risk of stroke, systemic embolism and mortality in patients with NVAF [1].

VKAs, such as acenocoumarol and warfarin, act by inhibiting gamma carboxylation, thus preventing the action of vitamin K-dependent factors II, VII, IX and X. They are characterized by having a tight therapeutic margin with a highly variable individual response, as well as dietary and drug interactions, which make periodic analytical controls necessary to monitor the level of anticoagulation [1]. They were the first anticoagulants to be used to treat NVAF, as well as the only therapeutic option until DOACs came onto the market a few years ago [2-4]. Even so, VKAs are still used throughout the world [2,5,6], and they are the treatment of first choice in Spain, according to the Ministry of Health [7]. The use of VKAs is complicated by a narrow therapeutic window and an unpredictable dose-response relationship, which lead to frequent bleeding complications or insufficient anticoagulation. Such variations in the response to the dose are markedly influenced by pharmacokinetic aspects, which are determined by genetic and environmental factors, and possibly others that have not yet been identified [8].

Both molecules act as vitamin $\mathrm{K}$ antagonists and have similarities and differences at various levels, particularly those of a pharmacokinetic nature acting at the level of genetic polymorphisms. Acenocoumarol and warfarin are not completely equivalent. One of the most relevant differences between them is their half-lives. Acenocoumarol has a $1.8 \mathrm{~h}$ halflife [9], while warfarin has a half-life of 24-33 h [10]. Furthermore, genetic polymorphisms affect drug metabolism differently depending on the type of VKA. The isoenzyme CYP2C9 may be more important for metabolising warfarin than acenocoumarol [11]. VKA use also differs from country to country: for example, the most widely used VKA in Spain and the Netherlands is acenocoumarol [12-14], whereas in the United States and other European countries it is warfarin [2,6]. In Spain, acenocoumarol is more widely used than warfarin probably because its use was authorized sooner, in 1956 [15], and because its shorter half-life facilitates faster control of its bleeding adverse effects.

Most of the scientific evidence related to this group of drugs comes primarily from studies of warfarin, the results of which are frequently generalized to acenocoumarol. However, few studies have been published that justify this generalization by comparing different aspects of the two drugs.

It is of fundamental importance to know which of the drugs provides the best control of anticoagulation over a particular period.

The degree of anticoagulation control of a patient is measured as their time in therapeutic range (TTR). One of the methods used for this purpose is the Rosendaal method, which enables the percentage of time the patient is within the therapeutic range to be calculated, with a TTR $>65 \%$ after six months of anticoagulation treatment being considered a good level of control [1]. Studies in our environment using this method show poor control, with a value of $39 \%$, and no significant differences between the two types of VKA [16]. Poor control of anticoagulation is associated with an increase in the risk of stroke, bleeding and all-cause mortality $[17,18]$. The management of VKAs is associated with poor control routine, especially at the start of anticoagulation. Not all countries have the same degree of anticoagulation control. There is better control of anticoagulation with VKAs in Europe than in North America [19]. Given the evidence of poor control with VKAs in many countries and the greater use of acenocoumarol in Spain, although most studies are concerned with warfarin, it is essential to study the differences in the degree of control with both VKAs in our environment. Furthermore, in clinical practice, it is common to switch patients who do not achieve good control with acenocoumarol to warfarin treatment, with the aim of improving the anticoagulation control. The longer half-life and duration of 
action of warfarin can be erroneously associated with increased drug stability and potential better TTR control.

The objective of this study is to determine whether there are differences between acenocoumarol and warfarin in terms of their degrees of anticoagulation control. This was addressed by assessing the TTR and identifying the factors associated with poor VKA anticoagulation control in patients with NVAF.

\section{Materials and Methods}

\subsection{Design and Study Population}

The present aim of the Fantas-TIC Study is to determine the degree of the anticoagulation control with acenocoumarol or warfarin in NVAF in Primary Care by as-sessing and comparing the TTR values. Factors associated with poor VKA anticoagula-tion control were also identified. To achieve the objective, a cross-sectional study was carried out with data obtained from the SIDIAP population database (Information System for Research in Primary Care) of 5,564,292 patients treated in primary care by the Catalan Institute of Health (ICS), representing $80 \%$ of the Catalan population. [20,21]. From the SIDIAP database, 97,350 patients with a diagnosis of AF for at least 12 months were identified (Figure 1). Patients included in the study had, on 1 January 2018, an active prescription for an anticoagulant. VKA anticoagulant treatments with acenocoumarol and warfarin were taken into account. Drug data was obtained on the basis of anatomic therapeutic chemical (ATC) codes [22].

SIDIAP includes anonymized clinical information from different data sources $[20,21]$ such as PC electronic health records (EHRs). Since 2006, it has contained patients' sociodemographic information, health conditions following the International Classification of Diseases (ICD) 10 codes [23], clinical parameters and general practitioner prescriptions. Since 2005, the SIDIAP database has included both laboratory and prescription data, with information based on ATC classification system codes [22] of the pharmaceutical products dispensed by Catalan community pharmacies.

\subsection{Inclusion and Exclusion Criteria}

We included primary care patients of the ICS receiving anticoagulant treatment with acenocoumarol or warfarin, diagnosed with NVAF one year before the study (as of 1 January 2018) and monitored in PC with at least six controls of the international normalized ratio (INR) during the year before the study. This criterion minimizes the variability of the INR that may occur when the treatment begins or when it is temporarily withdrawn. The inclusion and exclusion criteria are shown in Figure 1.

We excluded patients who were diagnosed with valvular FA (those with mitral stenosis or with a mechanical valve prosthesis) without anticoagulant treatment, those whose oral anticoagulant type at the time of the study could not be determined, pregnant women, patients with VKA controlled by the hospital INR, patients treated with DOACs and patients whose 6-month TTR the year prior to the study could not be calculated (Figure 1).

\subsection{Study Variables}

Main variable: Rosendaal time in therapeutic range (TTR) at 6 months in 2017 in patients anticoagulated with either of the VKAs acenocoumarol or warfarin, which are drugs included in the ATC code list [22]. Values of TTR $<65 \%$ at 6 months were considered to indicate poor anticoagulation control.

Secondary variables: sociodemographic variables, type of treatment, place of prescription, antecedent, cardiovascular antecedents, intracranial haemorrhage (ICH), morbidity, gastrointestinal bleeding (GIB), history of high risk of bleeding and other haemorrhages and scores calculated from real data of participants $\left(\mathrm{CHA}_{2} \mathrm{DS}_{2} \mathrm{VASc}\right.$ and HAS_BLESD). Diseases were classified as specified in the ICD10 code list [23]. 


\subsection{Statistical Analysis}

Data were cleaned by checking the minimum and maximum values of the variables, as well as by an analysis of missing data. The Kolmogorov-Smirnov test of normality was performed on the 2017 6-month TTR variable to check whether it was normally distributed in both acenocoumarol and warfarin patients.

Values of the 20176 -month TTR variable were categorized into poor (TTR $<65 \%$ ) and good (TTR $\geq 65 \%$ ) anticoagulation control. Having cleaned the database, a descriptive analysis of poor control of TTR was carried out with respect to the type of VKA and the characteristics of the patients. Statistically significant differences between the categories of the variables studied according to the type of medication were tested using a twoproportion Z-test. To measure the association between the type of VKA used for TTR control and the other variables, and to study the factors related to poor control of anticoagulation with VKA, adjusted odd ratios (ORs) were estimated by multivariate logistic regression. For each type of VKA and for each value of HAS-BLED and $\mathrm{CHA}_{2} \mathrm{DS}_{2} \mathrm{VASc}$, the mean TTR values and $95 \%$ confidence intervals (95\% CIs) were calculated and plotted.

Statistical analyses were carried out with Microsoft Excel 2010 and IBM SPSS Statistics version 20.0.

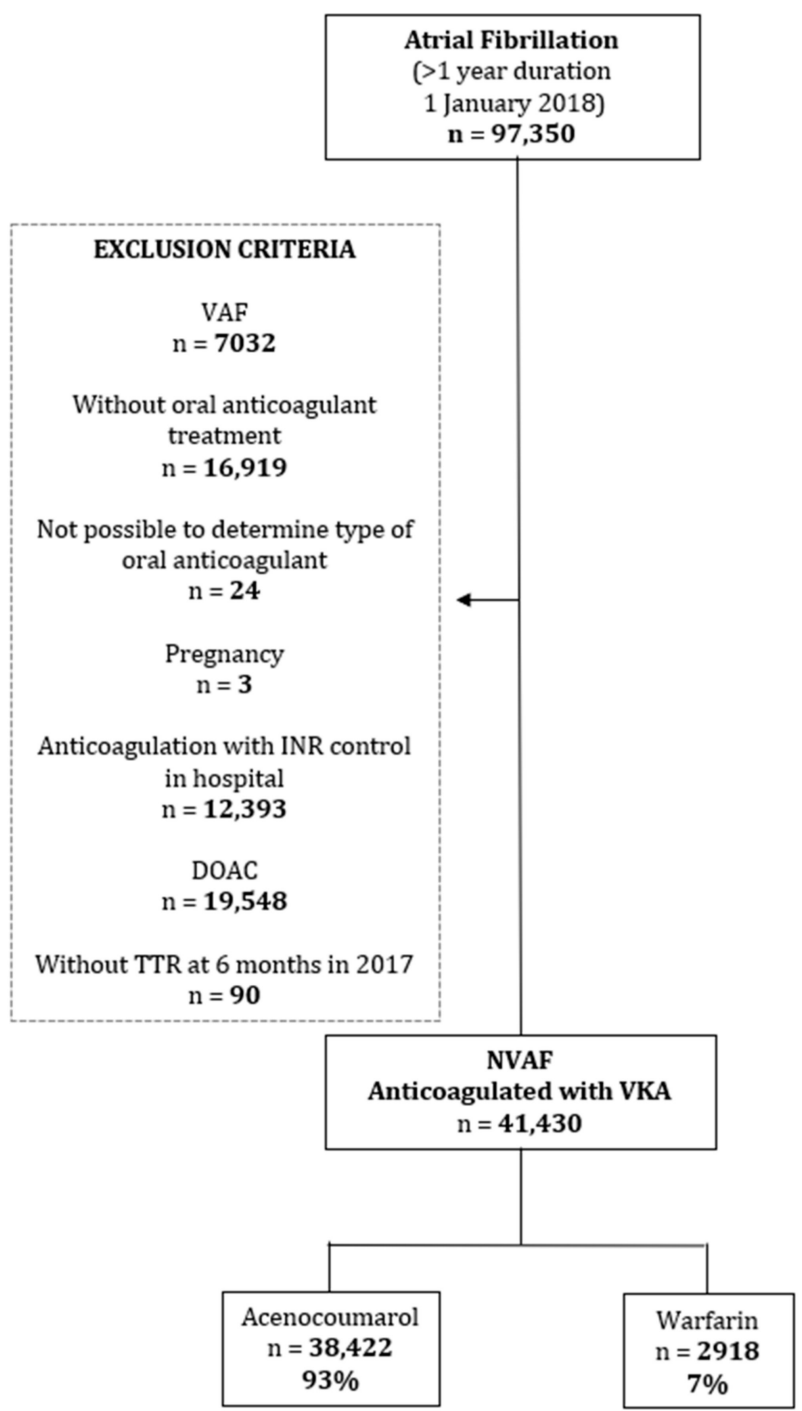

Figure 1. Flow diagram. 


\section{Results}

The final population studied included a total of 41,430 patients, with NVAF criteria, anticoagulated with VKA and controlled under PC, of whom 38,422 (93\%) were treated with acenocoumarol and $2918(7 \%)$ with warfarin. Table 1 shows the characteristics of the patients studied.

Table 1. Characteristics of patients in the study.

\begin{tabular}{|c|c|}
\hline Total & 41,340 \\
\hline \multicolumn{2}{|l|}{ Sex } \\
\hline Female & $20,241(49.0)$ \\
\hline Male & $21,099(51.0)$ \\
\hline Age in Years. mean (SD) & $78.4(9.0)$ \\
\hline \multicolumn{2}{|l|}{ Type of AVK } \\
\hline Acenocoumarol & $38,422(92.9)$ \\
\hline Warfarin & $2918(7.1)$ \\
\hline Oral Anticoagulation Prescription in Primary Care & $33,185(80.3)$ \\
\hline \multicolumn{2}{|l|}{ Cardiovascular History } \\
\hline Peripheral Arteriopathy & $2698(6.5)$ \\
\hline Ischaemic Heart Disease & 7494 (18.1) \\
\hline Aortic Atheromatosis & $399(1.0)$ \\
\hline Ischaemic Stroke or Transient Ischaemic Attack & $6421(15.5)$ \\
\hline Intracranial Haemorrhage & $363(0.9)$ \\
\hline \multicolumn{2}{|l|}{ Morbidity } \\
\hline Diabetes Mellitus & $13,552(32.8)$ \\
\hline Arterial Hypertension & $33,284(80.5)$ \\
\hline Heart Failure & $10,806(26.1)$ \\
\hline Renal Insufficiency & $12,303(29.8)$ \\
\hline \multicolumn{2}{|l|}{ Bleeding Risk History } \\
\hline Alcohol & $1721(4.2)$ \\
\hline Intracranial Aneurysm & $27(0.1)$ \\
\hline Portal Hypertension & $80(0.2)$ \\
\hline Liver Failure & $263(0.6)$ \\
\hline Hereditary Telangiectasia & $2(0.0)$ \\
\hline Active Aortic Aneurysm and Dissection & $612(1.5)$ \\
\hline Intestinal Angiodysplasia & $92(0.2)$ \\
\hline Haemorrhages Other Than Gastrointestinal and Intracranial & $567(1.4)$ \\
\hline Gastrointestinal Bleeding & $3272(7.9)$ \\
\hline \multirow{2}{*}{\multicolumn{2}{|c|}{$\begin{array}{c}\text { Scores } \\
\mathrm{CHA}_{2} \mathrm{DS}_{2} \mathrm{VASc}\end{array}$}} \\
\hline & \\
\hline 0 & $404(1.0)$ \\
\hline 1 & $2104(5.1)$ \\
\hline 2 & $7246(17.5)$ \\
\hline 3 & $14,656(35.5)$ \\
\hline$\geq 4$ & $16,930(41.0)$ \\
\hline \multicolumn{2}{|l|}{ HAS-BLED } \\
\hline 0 & $953(2.3)$ \\
\hline 1 & $14,548(35.2)$ \\
\hline 2 & $15,075(36.5)$ \\
\hline 3 & $7754(18.8)$ \\
\hline$\geq 4$ & $3010(7.3)$ \\
\hline eGFR $\mathrm{mL} / \mathrm{min} / 1.73 \mathrm{~m}^{2}$ & $61.2(18.9)$ \\
\hline \multicolumn{2}{|l|}{ Patients Treated Outside Primary Care Centre } \\
\hline Treated at Home & $4892(11.8)$ \\
\hline Treated in an Institution & $1636(4.0)$ \\
\hline
\end{tabular}

Quantitative variables are expressed as mean (standard deviation) and qualitative variables as $n(\%)$.

There was no difference in the poor control of TTR between the two types of VKA treatment (acenocoumarol, 38.9 vs. warfarin, 38.4; $p=0.610$ ) (Table 2). No statistically significant differences were observed in the bivariate analyses that compared poor control between the two types of VKA treatment for each patient variable studied (Table 2). 
Table 2. Description of poor control with respect to TTR $<65 \%$ at 6 months by type of treatment (acenocoumarol and warfarin) and patient characteristics.

\begin{tabular}{|c|c|c|c|c|c|c|c|}
\hline & \multicolumn{3}{|c|}{ Acenocoumarol } & \multicolumn{3}{|c|}{ Warfarin } & \multirow[b]{2}{*}{${ }^{\mathrm{a}} p$} \\
\hline & Total & TTR $<65 \%$ & $\%$ & Total & TTR $<65 \%$ & $\%$ & \\
\hline Total & 38,422 & 14,944 & 38.9 & 2918 & 1121 & 38.4 & 0.610 \\
\hline \multicolumn{8}{|l|}{ Sex } \\
\hline Female & 18,808 & 7626 & 40.5 & 1433 & 587 & 41.0 & 0.757 \\
\hline Male & 19,614 & 7318 & 37.3 & 1485 & 534 & 36.0 & 0.299 \\
\hline \multicolumn{8}{|l|}{ Age (years) } \\
\hline$<60$ & 862 & 370 & 42.9 & 72 & 27 & 37.5 & 0.371 \\
\hline $60-69$ & 4281 & 1610 & 37.6 & 397 & 145 & 36.5 & 0.670 \\
\hline $70-79$ & 12,558 & 4691 & 37.4 & 1085 & 390 & 35.9 & 0.357 \\
\hline$\geq 80$ & 20,721 & 8273 & 39.9 & 1364 & 559 & 41.0 & 0.440 \\
\hline \multicolumn{8}{|l|}{$\begin{array}{l}\text { Oral Anticoagulant Prescription in } \\
\text { Primary Care }\end{array}$} \\
\hline Yes & 30,938 & 11,964 & 38.7 & 2247 & 866 & 38.5 & 0.902 \\
\hline No & 7484 & 2980 & 39.8 & 671 & 255 & 38.0 & 0.357 \\
\hline \multicolumn{8}{|l|}{ Cardiovascular History } \\
\hline Peripheral Arteriopathy & 2492 & 1088 & 43.7 & 206 & 89 & 43.2 & 0.899 \\
\hline No & 35,930 & 13,856 & 38.6 & 2712 & 1032 & 38.1 & 0.598 \\
\hline Ischaemic Heart Disease & 6951 & 2855 & 41.1 & 543 & 222 & 40.9 & 0.931 \\
\hline No & 31,471 & 12,089 & 38.4 & 2375 & 899 & 37.9 & 0.588 \\
\hline Aortic Atheromatosis & 354 & 139 & 39.3 & 45 & 16 & 35.6 & 0.631 \\
\hline No & 38,068 & 14,805 & 38.9 & 2873 & 1105 & 38.5 & 0.649 \\
\hline Ischaemic Stroke or TIA & 5810 & 2351 & 40.5 & 611 & 252 & 41.2 & 0.709 \\
\hline No & 32,612 & 12,593 & 38.6 & 2307 & 869 & 37.7 & 0.367 \\
\hline Intracranial Haemorrhage & 334 & 156 & 46.7 & 29 & 16 & 55.2 & 0.381 \\
\hline No & 38,088 & 14,788 & 38.8 & 2889 & 1105 & 38.2 & 0.539 \\
\hline \multicolumn{8}{|l|}{ Morbidity } \\
\hline Diabetes mellitus & 12,549 & 5293 & 42.2 & 1003 & 406 & 40.5 & 0.294 \\
\hline No & 25,873 & 9651 & 37.3 & 1915 & 715 & 37.3 & 0.975 \\
\hline Arterial Hypertension & 30,947 & 12,047 & 38.9 & 2337 & 913 & 39.1 & 0.894 \\
\hline No & 7475 & 2897 & 38.8 & 581 & 208 & 35.8 & 0.159 \\
\hline Heart Failure & 9947 & 4320 & 43.4 & 859 & 363 & 42.3 & 0.506 \\
\hline No & 28,475 & 10,624 & 37.3 & 2059 & 758 & 36.8 & 0.653 \\
\hline Renal Insufficiency & 11,346 & 4752 & 41.9 & 957 & 417 & 43.6 & 0.309 \\
\hline No & 27,076 & 10,192 & 37.6 & 1961 & 704 & 35.9 & 0.124 \\
\hline \multicolumn{8}{|l|}{ Bleeding Risk History } \\
\hline Alcohol & 1564 & 711 & 45.5 & 157 & 71 & 45.2 & 0.955 \\
\hline No & 36,858 & 14,233 & 38.6 & 2761 & 1050 & 38.0 & 0.542 \\
\hline Intracranial Aneurysm & 26 & 12 & 46.2 & 1 & 1 & 100.0 & 0.290 \\
\hline No & 38,396 & 14,932 & 38.9 & 2917 & 1120 & 38.4 & 0.598 \\
\hline Portal Hypertension & 72 & 27 & 37.5 & 8 & 4 & 50.0 & 0.491 \\
\hline No & 38,350 & 14,917 & 38.9 & 2910 & 1117 & 38.4 & 0.585 \\
\hline Liver Failure & 242 & 116 & 47.9 & 21 & 11 & 52.4 & 0.696 \\
\hline No & 38,180 & 14,828 & 38.8 & 2897 & 1110 & 38.3 & 0.579 \\
\hline Hereditary Telangiectasia & 1 & 0 & 0.0 & 1 & 1 & 100.0 & 0.157 \\
\hline No & 38,421 & 14,944 & 38.9 & 2917 & 1120 & 38.4 & 0.593 \\
\hline Active Aortic Aneurysm and Dissection & 558 & 207 & 37.1 & 54 & 27 & 50.0 & 0.062 \\
\hline No & 37,864 & 14,737 & 38.9 & 2864 & 1094 & 38.2 & 0.444 \\
\hline Intestinal Angiodysplasia & 85 & 40 & 47.1 & 7 & 4 & 57.1 & 0.608 \\
\hline No & 38,337 & 14,904 & 38.9 & 2911 & 1117 & 38.4 & 0.590 \\
\hline $\begin{array}{l}\text { Haemorrhages Other Than } \\
\text { Gastrointestinal and Intracranial }\end{array}$ & 523 & 194 & 37.1 & 44 & 16 & 36.4 & 0.923 \\
\hline No & 37,899 & 14,750 & 38.9 & 2874 & 1105 & 38.4 & 0.617 \\
\hline
\end{tabular}


Table 2. Cont.

\begin{tabular}{|c|c|c|c|c|c|c|c|}
\hline & \multicolumn{3}{|c|}{ Acenocoumarol } & \multicolumn{3}{|c|}{ Warfarin } & \multirow[b]{2}{*}{${ }^{\mathrm{a}} p$} \\
\hline & Total & TTR $<65 \%$ & $\%$ & Total & TTR $<65 \%$ & $\%$ & \\
\hline Gastrointestinal Bleeding & 3028 & 1252 & 41.3 & 244 & 101 & 41.4 & 0.989 \\
\hline No & 35,394 & 13,692 & 38.7 & 2674 & 1020 & 38.1 & 0.581 \\
\hline \multicolumn{8}{|l|}{ Scores } \\
\hline \multicolumn{8}{|l|}{$\mathrm{CHA}_{2} \mathrm{DS}_{2} \mathrm{VASc}_{\mathrm{C}}$} \\
\hline 0 & 366 & 137 & 37.4 & 38 & 13 & 34.2 & 0.696 \\
\hline 1 & 1939 & 683 & 35.2 & 165 & 54 & 32.7 & 0.519 \\
\hline 2 & 6722 & 2402 & 35.7 & 524 & 170 & 32.4 & 0.129 \\
\hline 3 & 13,698 & 5148 & 37.6 & 958 & 382 & 39.9 & 0.157 \\
\hline$\geq 4$ & 15,697 & 6574 & 41.9 & 1233 & 502 & 40.7 & 0.424 \\
\hline \multicolumn{8}{|l|}{ HAS-BLED } \\
\hline 0 & 872 & 168 & 19.3 & 81 & 11 & 13.6 & 0.210 \\
\hline 1 & 13,530 & 2387 & 17.6 & 1018 & 190 & 18.7 & 0.410 \\
\hline 2 & 14,065 & 6285 & 44.7 & 1010 & 443 & 43.9 & 0.611 \\
\hline 3 & 7180 & 4210 & 58.6 & 574 & 320 & 55.7 & 0.177 \\
\hline$\geq 4$ & 2775 & 1894 & 68.3 & 235 & 157 & 66.8 & 0.648 \\
\hline \multicolumn{8}{|l|}{$\mathrm{eGFR} \mathrm{mL} / \mathrm{min} / 1.73 \mathrm{~m}^{2}$} \\
\hline$<15$ & 270 & 172 & 63.7 & 41 & 23 & 56.1 & 0.348 \\
\hline $15-29$ & 1678 & 825 & 49.2 & 164 & 84 & 51.2 & 0.616 \\
\hline $30-49$ & 7570 & 3292 & 43.5 & 639 & 274 & 42.9 & 0.766 \\
\hline$\geq 50$ & 25,887 & 9537 & 36.8 & 1926 & 679 & 35.3 & 0.164 \\
\hline Lost & 3017 & 1118 & 37.1 & 148 & 61 & 41.2 & 0.307 \\
\hline \multicolumn{8}{|l|}{$\begin{array}{c}\text { Patients Treated Outside Primary } \\
\text { Care Centre }\end{array}$} \\
\hline Treated at Home & 4504 & 2149 & 47.7 & 388 & 184 & 47.4 & 0.912 \\
\hline No & 33,918 & 12,795 & 37.7 & 2530 & 937 & 37.0 & 0.491 \\
\hline Treated in an Institution & 1546 & 756 & 48.9 & 90 & 48 & 53.3 & 0.414 \\
\hline No & 36,876 & 14,188 & 38.5 & 2828 & 1073 & 37.9 & 0.575 \\
\hline
\end{tabular}

The results of the logistic regression did not show an association between the type of treatment and poor anticoagulation control when adjusted for the effects of the other variables (Table 3). Female sex and being younger than 60 years of age were patient variables associated to poor control. Other patient variables related to poor anticoagulation control were a cardiovascular history of peripheral arterial disease and ischaemic heart disease, as well as diabetes mellitus (DM), heart failure (HF) and renal insufficiency (RI), a history of ICH or GIB, a history of alcoholism and liver failure (LF). In contrast, oral anticoagulant prescription in PC and arterial hypertension were lightly protective factors of poor control. Receiving care outside of a PC centre was also related to poor anticoagulation control, i.e., patients whose care needs were provided at home or in institutional settings were more likely to show poor control than those who were attended in a PC centre.

The six-month TTR distributions based on HAS-BLED values by drug type are shown in Figure 2. The risk of bleeding became greater as the score increased. For both treatments, a score of 3 or more on this scale represents poor TTR control.

The six-month TRT distribution according to the $\mathrm{CHA}_{2} \mathrm{DS}_{2} \mathrm{VASc}$ scores is shown in Figure 3 . The thromboembolic risk became greater as the scale score increased. The scores on the scale remained in the range of good TTR control for both VKAs. For acenocoumarol, all the $\mathrm{CHA}_{2} \mathrm{DS}_{2} \mathrm{VASc}$ scores were in the range of good TTR control, with anticoagulation control levels being worse when scores were 0 or $\geq 4$. For warfarin, on the other hand, higher $\mathrm{CHA}_{2} \mathrm{DS}_{2}$ VASc scores were linked to worse anticoagulation control. 
Table 3. Association of poor control of TTR by treatment, adjusted for other patient variables.

\begin{tabular}{|c|c|c|c|}
\hline & $\mathrm{OR}_{\mathrm{adj}}$ & $95 \%$ CI & $p$ \\
\hline \multicolumn{4}{|l|}{ Type of anticoagulant } \\
\hline Acenocoumarol & 1 & & \\
\hline Warfarin & 0.96 & $0.88-1.03$ & 0.268 \\
\hline \multicolumn{4}{|l|}{ Sex } \\
\hline Female & 1 & & \\
\hline Male & 0.87 & $0.83-0.91$ & $<0.001$ \\
\hline \multicolumn{4}{|l|}{ Age (years) } \\
\hline$<60$ & 1 & & \\
\hline $60-69$ & 0.82 & $0.71-0.95$ & 0.010 \\
\hline $70-79$ & 0.78 & $0.68-0.90$ & $<0.001$ \\
\hline$\geq 80$ & 0.82 & $0.72-0.94$ & 0.004 \\
\hline Oral Anticoagulant Prescription in Primary Care & 0.95 & $0.90-1.00$ & 0.036 \\
\hline \multicolumn{4}{|l|}{ Cardiovascular History } \\
\hline Peripheral Arteriopathy & 1.17 & $1.08-1.27$ & $<0.001$ \\
\hline Ischaemic Heart Disease & 1.08 & $1.02-1.13$ & 0.006 \\
\hline Aortic Atheromatosis & 0.96 & $0.79-1.18$ & 0.723 \\
\hline Ischaemic Stroke or Transient Ischaemic Attack & 1.04 & $0.98-1.10$ & 0.213 \\
\hline Intracranial Haemorrhage & 1.35 & $1.10-1.67$ & 0.004 \\
\hline \multicolumn{4}{|l|}{ Morbidity } \\
\hline Diabetes Mellitus & 1.19 & $1.14-1.24$ & $<0.001$ \\
\hline Arterial Hypertension & 0.95 & $0.90-1.00$ & 0.034 \\
\hline Heart Failure & 1.18 & $1.12-1.23$ & $<0.001$ \\
\hline Renal Insufficiency & 1.13 & $1.08-1.18$ & $<0.001$ \\
\hline \multicolumn{4}{|l|}{ Bleeding Risk History } \\
\hline Alcohol & 1.38 & $1.25-1.53$ & $<0.001$ \\
\hline Intracranial Aneurysm & 1.36 & $0.63-2.91$ & 0.436 \\
\hline Portal Hypertension & 0.81 & $0.51-1.29$ & 0.372 \\
\hline Liver Failure & 1.37 & $1.07-1.77$ & 0.014 \\
\hline Hereditary Telangiectasia & 1.61 & $0.10-25.91$ & 0.736 \\
\hline Active Aortic Aneurysm and Dissection & 1.04 & $0.88-1.23$ & 0.673 \\
\hline Intestinal Angiodysplasia & 1.39 & $0.92-2.11$ & 0.116 \\
\hline $\begin{array}{c}\text { Haemorrhages Other Than Gastrointestinal and } \\
\text { Intracranial }\end{array}$ & 0.89 & $0.75-1.06$ & 0.202 \\
\hline Gastrointestinal Bleeding & 1.11 & $1.03-1.20$ & 0.005 \\
\hline \multicolumn{4}{|l|}{ Patients Treated Outside Primary Care Centre } \\
\hline Treated at Home & 1.33 & $1.25-1.42$ & $<0.001$ \\
\hline Treated in an Institution & 1.35 & $1.22-1.50$ & $<0.001$ \\
\hline
\end{tabular}




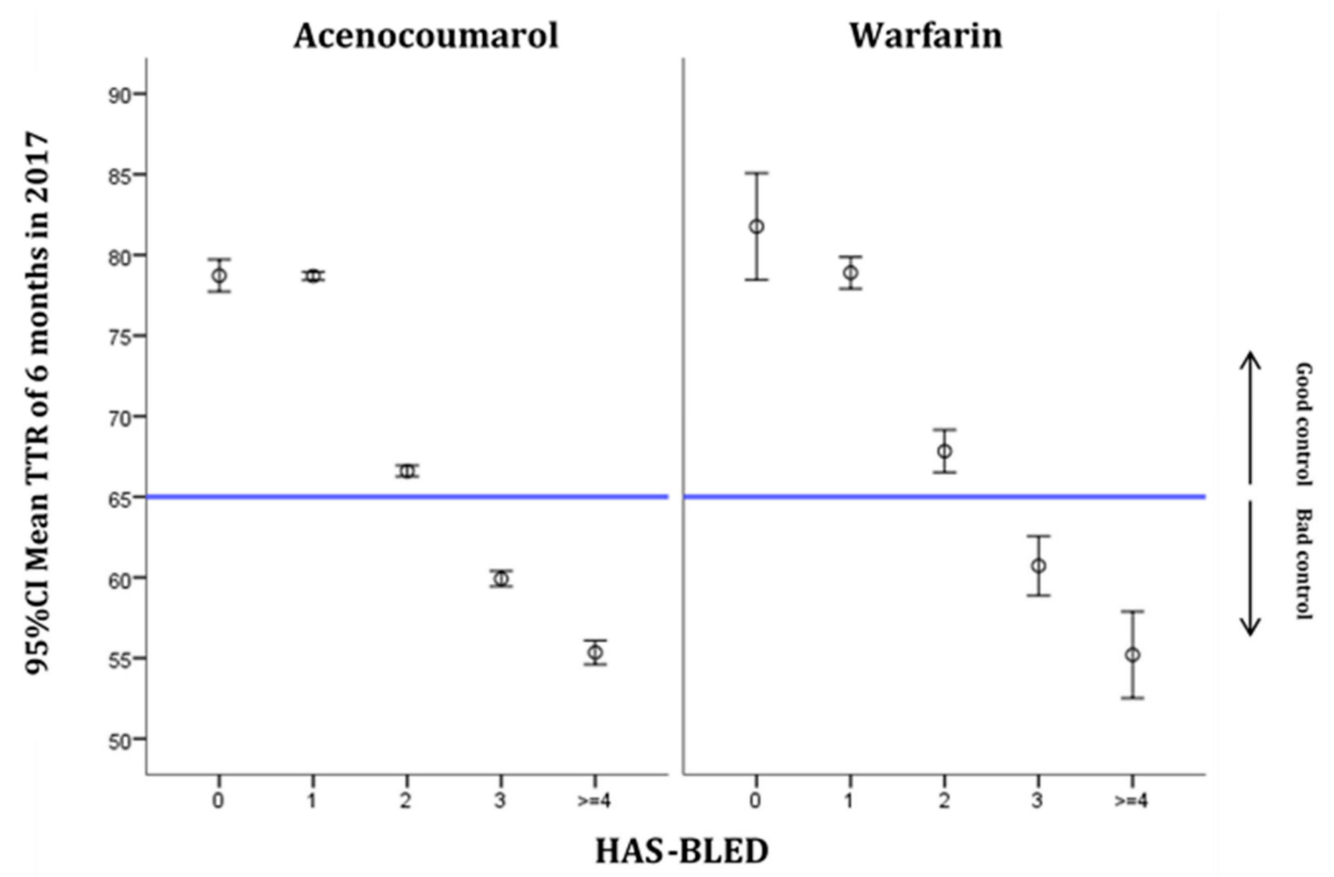

Figure 2. Distribution of TTR at 6 months in 2017 by HAS-BLED score and type of medication (mean and 95\% CI).

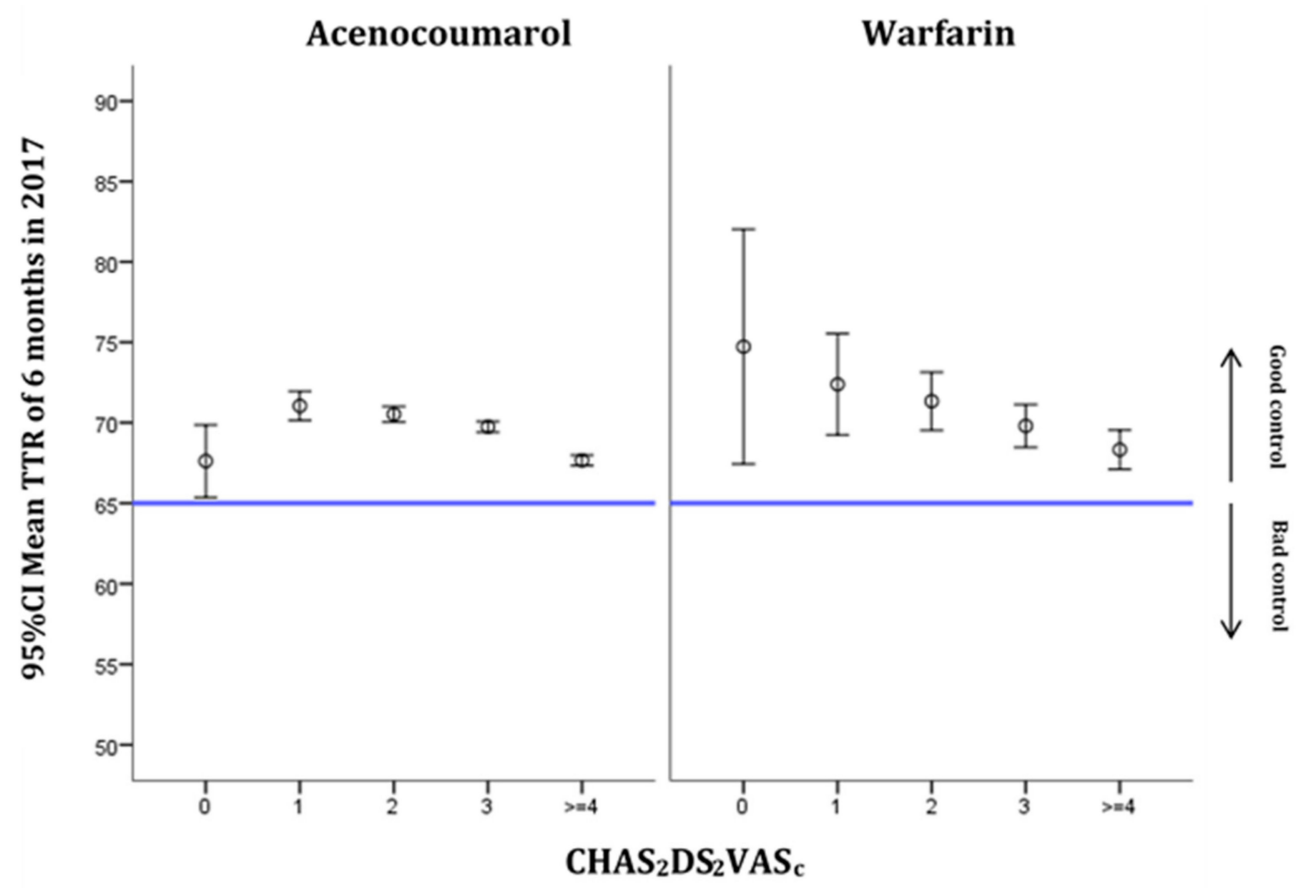

Figure 3. Distribution of TTR at 6 months in 2017 by $\mathrm{CHA}_{2} \mathrm{DS}_{2} \mathrm{VASc}$ score and type of medication (mean and $95 \% \mathrm{CI}$ ).

\section{Discussion}

The present study was carried out with real-word data from anticoagulated NVAF patients who were followed up in PC and treated with a VKA, with the use of acenocoumarol clearly predominating over the use of warfarin. To our knowledge, it is the first study to show, with recent real-word data, that there is no association between poor anticoagulation control and the type of VKA treatment. Similarly, we found no difference in poor control by type of VKA treatment in relation to any other patient variables studied. 
Examining the association of poor TTR control by type of VKA treatment when taking all other variables into account revealed no difference between the two treatments. However, an association was detected between poor control of anticoagulation with both acenocoumarol and warfarin and some patient characteristics. Female sex was associated with worse TRT control, as noted in a previous study [24]. This could be related to several factors, such as the more frequent occurrence in the female population of comorbidities such as dementia [24] and polypharmacy [25]. Specifically, polypharmacy in older people in Spain is more frequent in females [25] and is linked to an increased risk of drug interactions with anticoagulant treatment. At least 28 drugs are known to have interactions with acenocoumarol. These interactions are mainly pharmacokinetic, wherein acenocoumarol inhibits the cytochromes responsible for biotransformation [26]. Such drug interactions make it difficult to optimize doses and achieve good TRT control. The intensity of anticoagulation must be adapted to the established regime of medication at the start of anticoagulation. However, acute medications, such as Non-steroidal anti-inflammatory drugs (NSAIDs) and antibiotics that strongly disrupt coagulation for not inconsiderable periods of time, are less frequently taken into account.

Pharmacodynamic interactions are identical for acenocoumarol and warfarin [27], although the pharmacokinetic interactions do differ between these two drugs, since acenocoumarol is not metabolized by CYP3A4 as warfarin is [26]. Furthermore, the isoenzyme CYP2C9, the main cytochrome involved in the metabolism of coumarin anticoagulants, may be more important for the clearance of warfarin than of acenocoumarol. Some genetic polymorphisms related to this cytochrome increase the response to warfarin, but also to acenocoumarol [28]. According to recent studies, the correct dosage of acenocoumarol is largely determined by genetic variants, the age of the patient, sex, body mass index and the INR that it is wished to achieve [27]. These factors could explain $48 \%$ of the variation in dosage, and they need to be taken into account in order to improve anticoagulation control.

Regarding TTR control and patient age, our findings coincide with those of previous studies at the Spanish level, although the age ranges differ slightly; there is better INR control with both drugs in patients older than 60 years [24,29]. However, some published studies of the Chinese population indicate that, in patients treated with warfarin, being over 70 years of age is associated with poor control [30]. Such variation is probably related to the different geographic and cultural contexts and different sociodemographic characteristics, such as health care systems quality, organization, health care accessibility and domiciliary assistance [31]

Factors related to the risk of poor anticoagulation control included a cardiovascular history of peripheral artery disease and ischaemic heart disease, as well as bleeding (ICH or GIB). The morbidities that were related to poor control were DM, HF and RI, as well as a history of alcoholism and LF. Studies in our environment yielded similar results [32]. One of the patient variables with close association with poor TTR control was ICH. These patients should receive more attention and closer monitoring and would be candidates for switching to DOACs, on account of the ICH itself and because of their poor control of TTR. However, in some cases, patients with ICH could have advanced RI and be unable to make the switch to DOAC.

Our study, similarly to previous ones, reveals an association between alcohol consumption and poor control of TTR. Alcohol interacts with treatment with VKAs, enhancing their effect, and is related to poor anticoagulation control, which increases the risk of bleeding [33]. In some countries, such as Sweden, where alcohol consumption is high, this is the main risk factor for poor individual TTR control $(<60 \%)$ [34]. This study shows how in the group of patients with individual TTR values of $<60 \%$, the prevalence of alcohol consumption was three times that of the group with individual TTR values of $>70 \%$ [34]. In the same way, the increase in the HAS-BLED score worsened the degree of control of TTR for scores of $>3$ for both VKAs, acenocoumarol and warfarin. This could be because the scale contains variables related to RI, LF and alcoholism. The increase in the score on the $\mathrm{CHA}_{2} \mathrm{DS}_{2}$ VASc scale also yielded worse TTR values, but not to the extent as to be 
classified as poor control. This scale also contains variables, such as HF or DM, that have been associated with poorer TTR control or greater variability of INR [30,35]. On the other hand, differences in the confidence interval range could be related to the lower number of subjects treated with warfarin, and thus the lower number of subjects for both HAS-BLED and $\mathrm{CHA}_{2} \mathrm{DS}_{2} \mathrm{VASc}$ scoring zero compared to subjects treated with acenocoumarol.

One of the limitations of the study is its cross-sectional design, because cannot establish causality. However, it allows generating hypotheses, which opens the door to continuing studies of the similarities and differences between the two VKAs, given that most of the evidence is currently based on warfarin. This study considers data solely from PC and lacks hospital-based INR controls. This is another drawback, since it makes it difficult to generalize the results with confidence. On the other hand, the proportion of treatments with acenocoumarol (93\%) is much higher than that of treatments with warfarin $(7 \%)$ in our environment, although the use of population-based data means that the statistical power of the study is not compromised. The characteristics of the study population are similar to those of other studies of the Spanish population that claim to feature representative samples [24,29], and the population size considered enables the results from anticoagulated patients who have a diagnosis of NVAF and who are monitored in PC centres to be generalized. The degree of poor control of the participants treated with acenocoumarol and warfarin (38.9\% and $38.4 \%$, respectively) is similar to that of other studies in the Spanish setting, which have reported levels of $39.4 \%-47.3 \%$ of poor control with VKAs, with no differences between the treatments [29,32]. The few studies that have compared the differences in the degree of control in our setting reported Rosendaal TTR values of $<65 \%$ for $32.1 \%$ and $31.7 \%$ of patients receiving acenocoumarol and warfarin, respectively. These values are lower than those of our study but, consistently with our findings, exhibit no differences between the treatment types [16,32].

The results provide evidence that the two VKAs are very similar with respect to their ability to provide anticoagulation control at six months and allow us to identify characteristics of patients that are related to the risk of poor control for both VKA treatments. Current observations suggest that patients not achieving good control with either of the two VKA drugs would not improve control by switching VKA drug. However, in these cases, patients could benefit from switching to DOAC treatment.

These results will prompt further studies that will enable us to examine in even greater depth the differences between and similarities of these two VKAs, which continue to be the treatment of first choice for certain AF conditions. Studies of this nature could help to reduce thromboembolic and haemorrhagic risk while considering patient factors that are associated with poor control. Further studies must focus on identifying clinical support decision strategies to reduce poor TTR control degree and improving oral anticoagulant adequacy [36,37].

Author Contributions: M.R.D.L. is the main author of the study and has contributed in the idea, design and execution of the study work, the data manager process of the database, data analysis, interpretation of results, scientific writing of the article and review end of manuscript. N.C.-Q. and Z.H.R. are the corresponding authors and have contributed in: interpretation of results, scientific writing of the article and final revision of the manuscript. C.A.M., has contributed to the idea, design and execution of the study work, the data manager process of the database, data analysis, interpretation of results, A.Q.G. has contributed to the idea, design and execution of the study work, the data manager process of the database, scientific writing of the article and final revision of the manuscript. E.F.D. has contributed to the final revision of the manuscript. D.R.C. has contributed to the final revision of the manuscript E.C.B. has contributed to the final review of the manuscript and the data manager process of the database. J.F.-S. has contributed in the process of data manager of the database, data analysis, interpretation of results, scientific writing of the article. All authors have read and agreed to the published version of the manuscript.

Funding: Department of Health of the Generalitat de Catalunya, Strategic Plan for Research and Innovation in Health (PERIS), research project number SLT002/16/00146, and Intensification of Specialist Physicians grant SLT008/18/00021. 
Institutional Review Board Statement: The study was conducted according to the guidelines of the Declaration of Helsinki, and approved by the Institutional Review Board (or Ethics Committee) of IDIAP Jordi Gol (protocol code P17/091, 15 March 2017).

Informed Consent Statement: Not applicable.

Data Availability Statement: The data that support the findings of this study were obtained from the SIDIAP database (Information System for Research in Primary Care). This database is representative of the Catalan population. Restrictions apply to the availability of these data, which were used under license for this study. The authors have no authorization to share the data.

Acknowledgments: The authors thank the following Departments for their contribution: Primary Care Management of the Catalan Institute of Health, Information Systems of the Primary Care Services, Regional Management and Primary Care Management of the Terres de l'Ebre, Unit of Information Systems of the Regional Management Terres de l'Ebre, Functional Competences Centre of the ECAP of the Information Systems Area and SIDIAP.

Conflicts of Interest: M.R.D.L. declares having received funding to attend Bayer conferences, and partial sponsorship of a study funded by Bayer. C.A.M., A.Q.G., D.R.C., and J.F.-S. declares having received partial sponsorship of a study funded by Bayer. Z.H.R. declares having received funding to attend and participate in conferences Almirall and Boehringer, and partial sponsorship of a study funded by Bayer. E.F.D. declares having received funding to attend meetings sponsored by MSD and GlaxoSmithKline, and having received partial sponsorship of a study funded by Bayer. None of the sponsors were involved in the design and conduct of the study; the collection, management, analysis, and interpretation of the data; or the preparation, review or approval of the manuscript, or in the decision to submit it for publication.

\section{References}

1. Programa d'harmonització farmacoterapèutica, 2018. Pautes per a l'harmonització de l'ús d'anticoagulants orals per a la prevenció de l'ictus i l'embòlia sistèmica en pacients amb fibril-lació auricular. Servei Català de la Salut. Departament de Salut. Generalitat de Catalunya, 2018; pp. 1-76. Available online: https:/ / catsalut.gencat.cat/web/.content/minisite/catsalut/ proveidors_professionals/medicaments_farmacia/harmonitzacio/pautes/anticoagulants-orals-fibrilacio-auricular/pautesharmonitzacio-anticoagulants-orals-en-fibrilacio-auricular.pdf (accessed on 14 December 2020).

2. Kirchhof, P.; Benussi, S.; Kotecha, D.; Ahlsson, A.; Atar, D.; Casadei, B.; Castellá, M.; Diener, H.; Heidbuchel, H.; Hendriks, J.; et al. Guía ESC 2016 sobre el diagnóstico y tratamiento de la fibrilación auricular, desarrollada en colaboración con la EACTS. Rev. Esp. Cardiol. 2017, 70, e1-e84. [CrossRef]

3. Coleman, C.I.; Briere, J.-B.; Fauchier, L.; Levy, P.; Bowrin, K.; Toumi, M.; Millier, A.; Taieb, V.; Wu, O. Meta-analysis of real-world evidence comparing non-vitamin $\mathrm{K}$ antagonist oral anticoagulants with vitamin $\mathrm{K}$ antagonists for the treatment of patients with non-valvular atrial fibrillation. J. Mark. Access Health Policy 2019, 7, 1574541. [CrossRef] [PubMed]

4. Hindricks, G.; Potpara, T.; Dagres, N.; Arbelo, E.; Bax, J.J.; Blomström-Lundqvist, C.; Boriani, G.; Castella, M.; Dan, G.A.; Dilaveris, P.E.; et al. 2020 ESC Guidelines for the diagnosis and management of atrial fibrillation developed in collaboration with the European Association for Cardio-Thoracic Surgery (EACTS). Eur. Heart J. 2021, 42, 373-498. [CrossRef]

5. Steffel, J.; Verhamme, P.; Potpara, T.S.; Albaladejo, P.; Antz, M.; Desteghe, L.; Haeusler, K.G.; Oldgren, J.; Reinecke, H.; Roldan-Schilling, V.; et al. The 2018 European Heart Rhythm Association Practical Guide on the use of non-Vitamin K antagonist oral anticoagulants in patients with atrial fibrillation. Eur. Heart J. 2018, 39, 1330-1393. [CrossRef] [PubMed]

6. January, C.T.; Wann, L.S.; Calkins, H.; Chen, L.Y.; Cigarroa, J.E.; Cleveland, J.C.; Ellinor, P.T.; Ezekowitz, M.D.; Field, M.E.; Furie, K.L.; et al. 2019 AHA/ACC/HRS Focused Update of the 2014 AHA/ACC/HRS Guideline for the Management of Patients With Atrial Fibrillation: A Report of the American College of Cardiology/American Heart Association Task Force on Clinical Practice Guidelines and the Heart R. Circulation 2019, 140, e125-e151. [CrossRef]

7. Ministerio de Sanidad. Servicios Sociales e Igualdad. Agencia Española de Medicamentos y Productos Sanitarios. Informe de Posicionamiento Terapéutico UT-ACOD/V5/211120162016 Criterios y recomendaciones generales para el uso de nuevos anticoagulantes orales (NACO) en la prevención del ictus y la embolia sistémica en pacientes con fibrilación auricular no valvular. Available online: https:/ / www.aemps.gob.es/medicamentosUsoHumano/informesPublicos/docs/criterios-anticoagulantesorales.pdf (accessed on 16 December 2020).

8. Lin, P.J. Reviewing the reality: Why we need to change. Eur. Hear. J. Suppl. 2005, 7, 15-20. [CrossRef]

9. Thijssen, H.H.W.; Drittij, M.J.; Vervoort, L.M.T.; De Vries-Hanje, J.C. Altered pharmacokinetics of R- and S-acenocoumarol in a subject heterozygous for CYP2C9*3. Clin. Pharmacol. Ther. 2001, 70, 292-298. [CrossRef] [PubMed]

10. Kelly, J.G.; O’Malley, K. Clinical Pharmacokinetics of Oral Anticoagulants. Clin. Pharmacokinet. 1979, 4, 1-15. [CrossRef] [PubMed]

11. Ufer, M. Comparative pharmacokinetics of vitamin K antagonists warfarin, phenprocoumon and acenocoumarol. Clin. Pharmacokinet. 2005, 44, 1227-1246. [CrossRef] 
12. Barón Esquivias, G.; Escolar Albaladejo, G.; Zamorano, J.L.; Betegón Nicolás, L.; Canal Fontcuberta, C.; de Salas-Cansado, M.; Rubio-Rodríguez, D.; Rubio-Terrés, C. Cost-effectiveness Analysis Comparing Apixaban and Acenocoumarol in the Prevention of Stroke in Patients With Nonvalvular Atrial Fibrillation in Spain. Rev. Española Cardiol. (English Ed.) 2015, 68, 680-690. [CrossRef]

13. González-Juanatey, J.R.; Álvarez-Sabin, J.; Lobos, J.M.; Martínez-Rubio, A.; Reverter, J.C.; Oyagüez, I.; González-Rojas, N.; Becerra, V. Cost-effectiveness of Dabigatran for Stroke Prevention in Non-valvular Atrial Fibrillation in Spain. Rev. Española Cardiol. (English Ed.) 2012, 65, 901-910. [CrossRef] [PubMed]

14. Lekuona, I.; Anguita, M.; Zamorano, J.L.; Rodríguez, J.M.; Barja de Soroa, P.; Pérez-Alcántara, F. Would the Use of Edoxaban Be Cost-effective for the Prevention of Stroke and Systemic Embolism in Patients With Nonvalvular Atrial Fibrillation in Spain? Rev. Española Cardiol. (English Ed.) 2019, 72, 398-406. [CrossRef]

15. FICHA TECNICA SINTROM $1 \mathrm{mg}$ COMPRIMIDOS. Available online: https://cima.aemps.es/cima/dochtml/ft/5899 4/FichaTecnica_58994.html\#7-titular-de-la-autorizaci\%20-n-de-commercialization\%20and\%20therefore \%20had\%20a\%20 broader\%20experience\%20of\%20use\%20prior\%20to\%20warfarin (accessed on 21 April 2021).

16. Barrios, V.; Escobar, C.; Prieto, L.; Lobos, J.M.; Polo, J.; Vargas, D. Control of Anticoagulation with Warfarin or Acenocoumarol in Spain. Do They Differ? Rev. Esp. Cardiol. 2015, 68, 1181-1182. [CrossRef] [PubMed]

17. Cancino, R.S.; Hylek, E.M.; Reisman, J.I.; Rose, A.J. Comparing patient-level and site-level anticoagulation control as predictors of adverse events. Thromb. Res. 2014, 133, 652-656. [CrossRef] [PubMed]

18. Gallagher, A.M.; Setakis, E.; Plumb, J.M.; Clemens, A.; van Staa, T.-P. Risks of stroke and mortality associated with suboptimal anticoagulation in atrial fibrillation patients. Thromb. Haemost. 2011, 106, 968-977. [CrossRef] [PubMed]

19. Mearns, E.S.; White, C.M.; Kohn, C.G.; Hawthorne, J.; Song, J.S.; Meng, J.; Schein, J.R.; Raut, M.K.; Coleman, C.I. Quality of vitamin $\mathrm{K}$ antagonist control and outcomes in atrial fibrillation patients: A meta-analysis and meta-regression. Thromb. J. 2014, 12, 14. [CrossRef] [PubMed]

20. Bolíbar, B.; Fina Avilés, F.; Morros, R.; Del Mar Garcia-Gil, M.; Hermosilla, E.; Ramos, R.; Rosell, M.; Rodríguez, J.; Medina, M.; Calero, S.; et al. Base de datos SIDIAP: La historia clínica informatizada de Atención Primaria como fuente de información para la investigación epidemiológica. Med. Clin. (Barc.) 2012, 138, 617-621. [CrossRef] [PubMed]

21. Del Mar García-Gil, M.; Hermosilla, E.; Prieto-Alhambra, D.; Fina, F.; Rosell, M.; Ramos, R.; Rodriguez, J.; Williams, T.; Van Staa, T.; Bolíbar, B. Construction and validation of a scoring system for the selection of high-quality data in a Spanish population primary care database (SIDIAP). Inform. Prim. Care 2012, 19, 135-145. [CrossRef] [PubMed]

22. WHOCC WHOCC_ATC/DDD Index. Available online: https://www.whocc.no/atc_ddd_index/ (accessed on 26 November 2020).

23. World Health Organization (WHO); Classification of Diseases (ICD). Available online: https:/ /www.who.int/classifications / classification-of-diseases (accessed on 26 November 2020).

24. García-Sempere, A.; Hurtado, I.; Bejarano-Quisoboni, D.; Rodríguez-Bernal, C.; Santa-Ana, Y.; Peiró, S.; Sanfélix-Gimeno, G. Quality of INR control and switching to non-Vitamin K oral anticoagulants between women and men with atrial fibrillation treated with Vitamin K Antagonists in Spain. A population-based, real-world study. PLoS ONE 2019, 14, e0211681. [CrossRef] [PubMed]

25. Carmona-Torres, J.M.; Cobo-Cuenca, A.I.; Recio-Andrade, B.; Laredo-Aguilera, J.A.; Martins, M.M.; Rodríguez-Borrego, M.A. Prevalence and factors associated with polypharmacy in the older people: 2006-2014. J. Clin. Nurs. 2018, 27, 2942-2952. [CrossRef] [PubMed]

26. Gschwind, L.; Rollason, V.; Lovis, C.; Boehlen, F.; Bonnabry, P.; Dayer, P.; Desmeules, J.A. Identification and weighting of the most critical "real-life" drug-drug interactions with acenocoumarol in a tertiary care hospital. Eur. J. Clin. Pharmacol. 2013, 69, 617-627. [CrossRef] [PubMed]

27. Teichert, M.; Eijgelsheim, M.; Rivadeneira, F.; Uitterlinden, A.G.; van Schaik, R.H.N.; Hofman, A.; De Smet, P.A.G.M.; van Gelder, T.; Visser, L.E.; Stricker, B.H.C. A genome-wide association study of acenocoumarol maintenance dosage. Hum. Mol. Genet. 2009, 18, 3758-3768. [CrossRef] [PubMed]

28. Visser, L.E.; Van Vliet, M.; Van Schaik, R.H.N.; Kasbergen, A.A.H.; De Smet, P.A.G.M.; Vulto, A.G.; Hofman, A.; Van Duijn, C.M.; Stricker, B.H.C. The risk of overanticoagulation in patients with cytochrome P450 CYP2C9*2 or CYP2C9*3 alleles on acenocoumarol or phenprocoumon. Pharmacogenetics 2004, 14, 27-33. [CrossRef] [PubMed]

29. Barrios, V.; Escobar, C.; Prieto, L.; Osorio, G.; Polo, J.; Lobos, J.M.; Vargas, D.; García, N. Anticoagulation Control in Patients With Nonvalvular Atrial Fibrillation Attended at Primary Care Centers in Spain: The PAULA Study. Rev. Española Cardiol. (English Ed.) 2015, 68, 769-776. [CrossRef]

30. Liang ADEF, H.-F.; Du, X.C.; Zhou, Y.-C.B.; Yang, X.-Y.B.; Xia BDF, S.-J.; Dong ADEF, J.-Z.; Lip, G.Y.; Ma, C.-S.; Squibb, M.; Ingelheim, B. Control of Anticoagulation Therapy in Patients with Atrial Fibrillation Treated with Warfarin: A Study from the Chinese Atrial Fibrillation Registry. Med. Sci. Monit. 2019, 25, 4691-4698. [CrossRef]

31. Li, X.; Krumholz, H.M.; Yip, W.; Cheng, K.K.; De Maeseneer, J.; Meng, Q.; Mossialos, E.; Li, C.; Lu, J.; Su, M.; et al. Quality of primary health care in China: Challenges and recommendations. Lancet 2020, 395, 1802-1812. [CrossRef]

32. Sánchez, M.A.; Martínez, V.B.; Fillat, Á.C. Quality of Vitamin K Antagonist Anticoagulation in Spain: Prevalence of Poor Control and Associated Factors on behalf of the CALIFA study researchers. Rev. Española Cardiol. (English Ed.) 2015. [CrossRef]

33. Dharmarajan, L.; Dharmarajan, T.S. Prescribing warfarin appropriately to meet patient safety goals. Am. Health Drug Benefits 2008, 1, 26-32. [PubMed] 
34. Björck, F.; Kadhim, H.; Själander, A. Predictors for INR-control in a well-managed warfarin treatment setting. J. Thromb. Thrombolysis 2019, 47, 227-232. [CrossRef]

35. García-Fernández, A.; Esteve-Pastor, M.A.; Roldán-Rabadán, I.; Muñiz, J.; Ruiz Ortiz, M.; Cequier, Á.; Bertomeu-Martínez, V.; Badimón, L.; Otero, D.; Anguita, M.; et al. Relationship of adverse events to quality of anticoagulation control in atrial fibrillation patients with diabetes: Real-world data from the FANTASIIA Registry. Ann. Med. 2020, 52, 300-309. [CrossRef]

36. Dalmau Llorca, M.R.; Gonçalves, A.Q.; Forcadell Drago, E.; Fernández-Sáez, J.; Hernández Rojas, Z.; Pepió Vilaubí, J.M.; Rodríguez Cumplido, D.; Morral Parente, R.M.; Aguilar Martín, C. A new clinical decision support tool for improving the adequacy of anticoagulant therapy and reducing the incidence of stroke in nonvalvular atrial fibrillation. Medicine (United States) 2018, 97, e9578. [CrossRef] [PubMed]

37. Rosa Dalmau Llorca, M.; Martín, C.A.; Carrasco-Querol, N.; Rojas, Z.H.; Drago, E.F.; Cumplido, D.R.; Vilaubí, J.M.P.; Blanco, E.C.; Gonçalves, A.Q.; Fernández-Sáez, J. Oral anticoagulant adequacy in non-valvular atrial fibrillation in primary care: A crosssectional study using real-world data (fantas-tic study). Int. J. Environ. Res. Public Health 2021, 18, 2244. [CrossRef] [PubMed] 